\title{
Review \\ Bench-to-bedside review: Mechanisms and management of hyperthermia due to toxicity
}

\author{
Florian Eyer and Thomas Zilker
}

Department of Clinical Toxicology, II Medizinische Klinik, Klinikum rechts der Isar, Technical University, D-81675 Munich, Germany

Corresponding author: Florian Eyer, Florian.Eyer@t-online.de

Published: 6 December 2007

This article is online at http://ccforum.com/content/11/6/236

(c) 2007 BioMed Central Ltd
Critical Care 2007, 11:236 (doi:10.1186/cc6177)

\begin{abstract}
Body temperature can be severely disturbed by drugs capable of altering the balance between heat production and dissipation. If not treated aggressively, these events may become rapidly fatal. Several toxins can induce such non-infection-based temperature disturbances through different underlying mechanisms. The drugs involved in the eruption of these syndromes include sympathomimetics and monoamine oxidase inhibitors, antidopaminergic agents, anticholinergic compounds, serotonergic agents, medicaments with the capability of uncoupling oxidative phosphorylation, inhalation anesthetics, and unspecific agents causing drug fever. Besides centrally disturbed regulation disorders, hyperthermia often results as a consequence of intense skeletal muscle hypermetabolic reaction. This leads mostly to rapidly evolving muscle rigidity, extensive rhabdomyolysis, electrolyte disorders, and renal failure and may be fatal. The goal of treatment is to reduce body core temperature with both symptomatic supportive care, including active cooling, and specific treatment options.
\end{abstract}

\section{Introduction}

Body temperature regulation is complex and requires a balance between heat production and dissipation. Hyperthermia occurs when metabolic heat production exceeds heat dissipation. Many exogenously administered drugs are capable of altering the body's ability to maintain a constant temperature.

Normal body temperature is approximately $37.0^{\circ} \mathrm{C}$, although this varies with the time of day. The Society of Critical Care Medicine has defined fever as a body temperature of $\geq 38.3^{\circ} \mathrm{C}$, which has gained wide acceptance [1]. Adaptive thermogenesis by heat production is controlled through hypothalamic regulation of the sympathetic nervous system [2]. The preoptic nucleus of the anterior hypothalamus responds to core temperature changes and regulates the autonomic nervous system, inducing either cutaneous vasodilatation, which dissipates heat, or vasoconstriction, which conserves heat [3]. Norepinephrine, dopamine and serotonin have all been suggested to play major roles in regulating hypothalamic control of body temperature [4]. Sympathetic nervous system activation contributes to effects on thermogenesis through cutaneous vasoconstriction and nonshivering thermogenesis [5]. Thus, drugs altering the hypothalamic levels of these neurotransmitters are capable of altering body temperature regulation [6]. Activation of the hypothalamic-pituitary-thyroid and the hypothalamic-pituitaryadrenal axes are adjacent mechanisms in regulating body core temperature that can be influenced by drugs that affect them. Nonshivering thermogenesis occurs primarily by uncoupling of oxidative phosphorylation through the activity of a group of mitochondrial proteins known as uncoupling proteins.

Uncontrolled hyperthermia is independently associated with increased morbidity and mortality [7]. Hyperthermia may cause rhabdomyolysis, liver failure, disseminated intravasal coagulation and multi-organ failure [8]. It accentuates excitotoxic neurotransmitter release, increases production of oxygen free radical species, accelerates cytoskeletal protein degradation, and increases the risk of seizures [9]. A recent publication demonstrates a nearly $30 \%$ mortality rate from all heat-related illness presenting to the emergency department; thus, early recognition and management of hyperthermic reactions is essential [10]. Besides the hazards that are inherent to hyperthermia, treatment of toxin-induced hyperthermia also has to account for toxin-specific complications (for example, malignant dysrhythmia after neuroleptic overdose) and may, therefore, become a challenge for the intensivist.

In this bench-to-bedside review we present seven conditions in which toxin-induced hyperthermia plays an essential role, discuss the underlying pathophysiology and suggest a clinical approach. These conditions are summarized in Table 1 and include: adrenergic fever caused, for example, by cocaine, amphetamines, designer drugs or monoamine

CNS = central nervous system; IPS = Infection Probability Score; MAO = monoamine oxidase; MDMA = 3,4-methylendioxymeth-amphetamine; $\mathrm{MH}=$ malignant hyperthermia; NMS = neuroleptic malignant syndrome; $\mathrm{PCP}=$ pentachlorphenol. 
Table 1

Major syndromes and causes of hyperthermia due to toxicity

\begin{tabular}{ll}
\hline Major syndromes & Implicated drugs \\
\hline Adrenergic fever & $\begin{array}{l}\text { Phenethylamines such as amphetamine, methamphetamine, MDMA; cocaine and MAO inhibitors } \\
\text { Antidopaminergic fever (NMS) }\end{array}$ \\
$\begin{array}{l}\text { Phenothiazines, butyrophenones; atypical neuroleptics such as olanzapine and clozapine; } \\
\text { metoclopramide and promethazine; acute withdrawal of anti-Parkinsonian agents }\end{array}$ \\
$\begin{array}{l}\text { Antispasmodics, antihistamines, anti-ulcer and anti-Parkinsonian drugs, neuroleptics or ingredients of } \\
\text { plants (for example, belladonna alkaloids) and mushrooms }\end{array}$ \\
$\begin{array}{l}\text { Drugs increasing serotonin-concentration in the CNS; combination of drugs (for example, MAO inhibitors } \\
\text { and tricyclic antidepressants); other drugs, including dextrometorphan, meperidine, L-dopa, } \\
\text { bromocriptine, tramadol, lithium and the MAO inhibitor linezolid }\end{array}$ \\
$\begin{array}{l}\text { PCP and salicylates } \\
\text { Uncoupling of oxidative phosphorylation }\end{array}$ \\
$\begin{array}{l}\text { Volatile anesthetics and depolarizing muscle relaxants } \\
\text { Drug induced fever }\end{array}$ \\
$\begin{array}{l}\text { Anticonvulsants, minocycline, antimicrobial agents, allopurinol, and heparin; virtually any drug capable of } \\
\text { causing fever via hypersensitivity mechanism }\end{array}$
\end{tabular}

CNS, central nervous system; MAO, monoamine oxidase; MDMA, 3,4-methylendioxymeth-amphetamine; NMS, neuroleptic malignant syndrome; PCP, pentachlorphenol.

oxidase (MAO) inhibitors; antidopaminergic fever with the classical presentation of the neuroleptic malignant syndrome (NMS); anticholinergic fever caused by anticholinergic properties of drugs; serotonergic fever that is, in the majority of cases, caused by a combination of drugs, but seldom occurs with single agent therapy and is typically classified as serotonin syndrome; uncoupling of oxidative phosphorylation, most frequently caused by pentachlorphenol and salicylates; inherited malignant hyperthermia $(\mathrm{MH})$; and drug induced fever that is not well defined resulting from inhomogeneous classes of drugs and underlying mechanisms and probably the most difficult to distinguish from infectious causes of fever during a multifaceted therapy in the intensive care unit (Table 2).

Since both recognition and treatment vary with the cause of hyperthermia, it is important for clinicians to understand the various presentations of, and treatments for, toxin-induced hyperthermic syndromes. The aim of this article is to provide intensivists with an overview of toxin-induced hyperthermic reactions, focusing on new concepts regarding its pathogenesis and treatment innovations.

\section{Pathology of toxin induced temperature disturbances and their treatment Adrenergic fever}

Intoxication with agents of the phenethylamine class (for example, amphetamine, methamphetamine, and currently the most popular sympathomimetic compound, 3,4-methylendioxymeth-amphetamine (MDMA)) as well as cocaine and MAO inhibitors may cause adrenergic fever [11]. MDMA and similar serotonergic agents may cause a central deregulation of thermogenesis through excessive serotonin and dopamine release [12,13]. A genetic vulnerability in which the enzyme CYP2D6 is not functional results in slower clearance and prolonged serum levels of MDMA. Along with elevated ambient temperature and poor hydration, motor activity increases the toxicity of stimulants such as amphetamine and MDMA. Besides catecholamine-mediated vasoconstriction with the inability to dissipate heat, psychomotor agitation leads to an increase in muscle activity with muscular heat production. Furthermore, thermoregulation within the hypothalamus has been suggested to be controlled by serotonin, dopamine and norepinephrine [4]. Direct and indirect stimulation of the hypothalamus by agents such as MDMA, methamphetamine, cocaine and MAO inhibitors activates the hypothalamic-pituitary-thyroid-adrenal axis, with subsequent thermogenesis and toxicity dependent on the level of circulating thyroid and adrenal hormones [14]. Significant elevation of norepinephrine has been demonstrated after MDMA as well as cocaine consumption. Acting through vascular $\alpha_{1}$-adrenoreceptors, norepinephrine induces vasoconstriction and impaired heat dissipation. In concert with elevated thyroid hormones, it also binds to and activates $\alpha_{1}$ - and $\beta_{3}$-adrenoreceptors regulating the activity of thermogenic tissues, such as brown fat, through uncoupling phosphorylation [15]. In summary, hypothalamic activation causes both impaired heat dissipation through vasoconstriction and excess heat generation through motor work and uncoupling. Hyperthermia (in addition to other sometimes life threatening symptoms) in this sort of intoxication is a sign of severe poisoning and heralds a poor outcome. Rigorous treatment of hyperthermia is therefore crucial.

The mainstay of therapy includes rapid and aggressive cooling. This should be conducted by various means of external cooling, including cool water submersion and evaporative cooling with misting and fans [16]. The ideal way of cooling a severely hyperthermic patient avoids intense 
Table 2

Differential diagnosis and specific treatment in syndromes associated with hyperthermia

\begin{tabular}{lll}
\hline Syndrome & Associated features & Treatment \\
\hline Adrenergic fever & $\begin{array}{l}\text { Hyperpyrexia, autonomic storm, convulsions, liver failure, } \\
\text { myocardial infarction, subarachnoid hemorrhage }\end{array}$ & $\begin{array}{l}\text { Sympatholytics (for example, carvedilol), } \\
\text { benzodiazepines }\end{array}$ \\
$\begin{array}{l}\text { Neuroleptic malignant } \\
\text { syndrome }\end{array}$ & $\begin{array}{l}\text { Slowly progressive generalized muscular rigidity (usually } \\
\text { over one to three days), mental status change, autonomic } \\
\text { instability, hyperthermia }\end{array}$ & $\begin{array}{l}\text { Bromocriptine, dantrolene, L-dopa, amantadine, muscle } \\
\text { relaxants }\end{array}$ \\
Anticholinergic fever & $\begin{array}{l}\text { Anticholinergic toxidrome: peripheral (dry red skin, } \\
\text { tachycardia) and central signs (mydriasis, tremor, } \\
\text { disorientation, coma) }\end{array}$ & Sedatives, physostigmin (controversial) \\
Serotonin syndrome & $\begin{array}{l}\text { Onset within 12 hours, self-limited hyperreflexia, } \\
\text { akathisia, tremor, sustained clonus, confusion, coma, } \\
\text { cognitive changes, autonomic instability (often hypertensive) }\end{array}$ & $\begin{array}{l}\text { Serotonin antagonists as cyproheptadine and } \\
\text { chlorpromazine, benzodiazepines, esmolol }\end{array}$ \\
Uncoupling of oxidative \\
phosphorylation & $\begin{array}{l}\text { Tachypnea, tachycardia, and marked diaphoresis (PCP) } \\
\text { Intractable acidosis, renal failure, pulmonary edema and } \\
\text { CNS disturbances (salicylates) }\end{array}$ & $\begin{array}{l}\text { PCP: supportive treatment, exchange transfusion } \\
\text { (controversial) }\end{array}$ \\
Malignant hyperthermia & $\begin{array}{l}\text { Fulminant muscle rigidity, hypermetabolic state, } \\
\text { hypercarbia }\end{array}$ & $\begin{array}{l}\text { Salicylates: hemodialysis } \\
\text { Discontinuation of anesthetics, dantrolene }\end{array}$ \\
Drug induced fever & $\begin{array}{l}\text { Mainly unspecific; broad clinical spectrum from looking } \\
\text { and feeling surprisingly well to looking severely ill and } \\
\text { profoundly septic; fever pattern varies broadly }\end{array}$ & $\begin{array}{l}\text { Discontinuation of any drugs not essentially needed; } \\
\text { distinguish from infectious causes, for example, using } \\
\text { the infection probability score }\end{array}$ \\
\hline
\end{tabular}

PCP, pentachlorphenol.

cooling of the skin, which stimulates shivering and vasoconstriction. Active cooling systems via a femoral artery catheter may be beneficial but in most cases are not needed. Benzodiazepine or barbiturate administration and, in severe cases, muscle relaxation should be used to stop myotonic or hyperkinetic thermogenesis [17]. Carvedilol reduces MDMA hyperthermia and rhabdomyolysis as an antagonist of $\beta_{1,2,3^{-}}$ adrenoceptor as well as $\alpha_{1}$-adrenoceptor. Thus, it is a more attractive treatment choice for sympathomimetic syndromes than other nonselective $\beta$-blockers, such as propranolol and nadolol. However, the only two animal studies supporting the usefulness of this therapy used much higher doses than are commonly used in humans [18]. Antipyretics have no role in therapy as they work by lowering the hypothalamic set point in febrile patients, a mechanism that has no relevance to the patient with hyperthermia [19]. Additional organ-orientated supportive therapy is, therefore, essential to all these patients (Table 3).

\section{Antidopaminergic fever: neuroleptic malignant syndrome}

The typical temperature disturbance disorder following the mechanism of antidopaminergic fever is NMS. It is a rare idiosyncratic reaction typically occurring in people taking neuroleptics or after the sudden withdrawal of dopamine agonists, with a reported prevalence between $0.02 \%$ and $0.4 \%$ [20]. Men are affected twice as often as women [21]. Typical clinical presentation of NMS is a syndrome of hyperthermia with temperatures $>38^{\circ} \mathrm{C}$ as a key finding, altered mental status, such as delirium, somnolence, coma and mutism, 'lead pipe' skeletal muscle rigidity, and autonomic dysfunction [21]. Autonomic dysfunction is mostly seen with tachycardia, hyper- or hypotension, and diaphoresis. Laboratory abnormalities include leukocytosis, elevated creatine kinase and liver transaminases, and low serum iron [22]. However, NMS can also occur in the absence of some or all of the classic clinical features and perhaps, therefore, presents a diagnostic challenge [23]. Differentiation between NMS and serotonin syndrome may be difficult. Speed of onset of symptoms as well as hyperreflexia and clonus are reported as the most distinguishing features between these two syndromes [6]. Serotonin syndrome typically presents acutely within 24 hours after starting medication with clonus, hyperreflexia and myoclonus, whereas NMS may be present at any time during drug course of neuroleptics, with peak symptoms not occurring for days [24].

The most common reported causatives of NMS are highpotency neuroleptics, such as haloperidol, but also atypical neuroleptics, such as olanzapine and clozapine [25], as well as non-neuroleptic drugs such as metoclopramide and promethazine [26]. Acute withdrawal of anti-Parkinsonian agents may be a further cause [27].

The pathophysiological mechanisms underlying NMS are only partly understood. Dopamine antagonists like phenothiazines or butyrophenones may cause hyperthermia by altering the thermoregulatory pathways in the anterior hypothalamus and increasing skeletal muscle rigidity through secondary extra- 
Table 3

\section{Generally accepted unspecific treatment options for hyperthermia}

Supportive treatment of hyperthermia

Discontinue any neuroleptic agent or precipitating drug

Maintain cardiorespiratory stability

Control airway as needed

Cool with ice, ice-water immersion, misting or fans or use intravenous cooling techniques in severe cases

Control rigidity, agitation or seizures with diazepam or lorazepam, titrated to effect

Stop cooling at $38^{\circ} \mathrm{C}$ (usually after 30 minutes)

Use rectal or urinary bladder thermocouple for monitoring temperature

Maintain euvolemic state using normal saline and maintain urinary output at 1 to $2 \mathrm{ml} / \mathrm{kg} /$ hour

Anticipate disseminated intravasal coagulation, rhabdomyolysis, renal and hepatic failure, and hyperkalemia

Diagnose and treat infections as encephalitis and meningitis when clinically suspected

Avoid antipyretics, phenothiazines, and butyrophenones

Consider dantrolene or muscle relaxants in refractory cases; intubation and ventilation are likely to be required

pyramidal hyperactivity [28]. Neuroleptic-induced myotoxicity with increased muscle metabolism resulting in hyperthermia and rigidity is a further, but not fully convincing, theory [29]. A recent theory favors sympathetic nervous system induced hyperactivity of the skeletal muscle. Predisposition to exaggerated sympathetic nervous system activity in response to emotional or psychological stress, along with variables such as psychotic distress or excessive dopamine antagonism, could pave the way to the induction of NMS [28]. This is supported by markedly elevated catecholamines in cerebral spinal fluid in patients with NMS; norepinephrine concentration was two times greater during acute illness in these patients than in matched controls during convalescence [30]. Similar findings have been reported for serotonin [31].

The first step in managing patients with NMS is recognition of the syndrome and removal of the offending drug. Physical cooling and supportive care is essential. The most commonly recommended drugs for treatment are bromocriptine and dantrolene. However, this is solely based on single case reports and retrospective reviews. Bromocriptine, a centrally acting dopamine analogue, is recommended at a dosage of $2.5 \mathrm{mg}$ every 8 hours given orally [32]. Sodium dantrolene (a non-specific muscle relaxant known for its ability to terminate episodes of malignant hyperthermia) is recommended through inhibition of calcium release from the sarcoplasmatic reticulum, thus decreasing muscle contraction [22]. Administration of sodium dantrolene may be considered in patients who develop temperatures above $40^{\circ} \mathrm{C}$, extensive rhabdomyolysis, coma and cardiorespiratory or renal failure [33,34]. It has been suggested that the initial dosage should be $2 \mathrm{mg} / \mathrm{kg}$ given intravenously. This dose may be repeated every 10 minutes, up to a total dose of $10 \mathrm{mg} / \mathrm{kg}$ per day. The oral dosage has ranged from 50 to $200 \mathrm{mg} /$ day. Hepatic toxicity may occur with doses $>10 \mathrm{mg} / \mathrm{kg} /$ day [34].

Other dopaminergic drugs, such as L-dopa or amantadine, have been reported to have a beneficial role [35]. As a supposed mechanism of heat production in NMS points to presynaptic involvement, a further therapeutic option includes mechanical ventilation and muscle relaxation in severe cases, which may result in rapid lowering of increased muscle activity and heat production [33].

\section{Anticholinergic fever}

Hyperthermia in anticholinergic fever is caused by both central and peripheral muscarinic receptor blockade whereas central effects depend on the drug's blood-brain permeability. There is a long list of anticholinergic agents, such as antispasmodics, antihistamines, anti-ulcer and anti-Parkinsonian drugs, neuroleptics and ingredients of plants (for example, belladonna alkaloids) and mushrooms. Central blockade may produce altered mental status, confusion, agitation, restlessness, seizures, and coma. Peripherally, anticholinergic blockade interferes with cutaneous loss of heat by impairing sweat gland function. Other symptoms comprise the anticholinergic toxidrome, including dry mouth and axillae, mydriasis, tachycardia, flushing, urinary retention and decreased bowel sounds [17]. Inability to lose heat and increased muscle activity both result in hyperthermia. Children are more likely to develop temperature disturbances than adults due to their immature thermoregulation mechanism.

Treatment of hyperthermia from anticholinergic poisoning is primarily supportive. Physostigmine, up to 1 to $2 \mathrm{mg} / \mathrm{h}$ intravenously, is an anticholinesterase agent that acts centrally and peripherally on both muscarinic and nicotinic receptors. However, due to its side effect profile (mainly induction of seizures and bradycardia), its use is rarely indicated [36]. External cooling and sedation or paralysis may be required for uncontrolled hyperthermia [17].

\section{Serotonergic fever: serotonin syndrome}

The serotonin syndrome is a potentially life-threatening adverse drug reaction that results from therapeutic drug use, intentional self-poisoning, or inadvertent interactions between drugs. It is not an idiopathic drug reaction but a predictable consequence of excess serotonergic agonsim of central and peripheral serotonergic receptors [37]. In the central nervous system (CNS), serotonin modulates attention, behavior, and thermoregulation. Serotonergic neurons are found primarily in the midline raphe nuclei, located in the brain stem from the midline to the medulla [38]. The neurons of the raphe in the 
lower pons and medulla participate in the regulation of nociception and motor tone. In the peripheral nervous system, serotonin is produced primarily by intestinal enterochromaffin cells and is involved in regulating gastrointestinal motility, vasoconstriction, uterine contraction, and bronchus-constriction [39]. The mechanism of serotonin syndrome is complex and involves interaction between the environment, central catecholamine release, the hypothalamic-pituitary-thyroidadrenal axis, the sympathetic nervous system, and skeletal muscle. Excellent reviews about the pathophysiology and clinical presentation of serotonin syndrome have been published recently $[6,40]$. Stimulation of the postsynaptic $5 \mathrm{HT} 1 \mathrm{~A}$ and $5 \mathrm{HT} 2 \mathrm{~A}$ receptors contributes to serotonin syndrome [41], but no single receptor is solely responsible. More recently, studies have placed emphasis on 5HT2A and D1-receptors in mediating hyperthermia [42].

Numerous compounds have been associated with serotonin syndrome, which is reviewed in several articles [39,41]. Essentially, any drug capable of increasing the concentration of serotonin in the CNS has the potential to cause this syndrome, although it is most common with a combination of drugs (for example, MAO inhibitors and tricyclic antidepressants). However, several drugs able to produce this syndrome are not immediately obvious: dextrometorphan, meperidine, L-dopa, bromocriptine, tramadol, lithium and, most recently, the MAO inhibitor linezolid [43]. The mechanisms by which various agents affect serotonin levels in the intersynaptic space include: first, blockade of reuptake (TCA, SSRIs, synthetic opioids); second, increased release of presynaptic serotonin (amphetamines, cocaine); third, increased synthesis (tryptophan); fourth, decreased catabolism (MAO inhibitors); fifth, binding of receptor by agonists (buspirone); and sixth, increased postsynaptic serotonin receptor sensitivity (lithium) [41]. The excess of serotonin produces a broad spectrum of clinical findings that may range from barely perceptible to lethal [40].

Although serotonin syndrome is often described as a clinical triad of mental status changes, autonomic hyperactivity and neuromuscular abnormalities, not all of these findings are consistently present in all patients [44]. No laboratory tests confirm the diagnosis of serotonin syndrome. Instead, the presence of tremor, clonus, rigor, or akathisia without additional extrapyramidal signs should lead clinicians to consider the diagnosis. The evolution of symptoms and their rate of change should also be reviewed to distinguish it from NMS. Some practicable decision-making rules to confirm the diagnosis have been published recently [40]. It has been further suggested that a rapid and complete response to antiserotoninergic agents (for example, cyproheptadine) is less likely among other hyperthermic disorders and strongly favors the diagnosis of the serotonin syndrome $[45,46]$.

Management of the serotonin syndrome involves the removal of the precipitating drugs, the application of supportive care comprising the administration of intravenous fluids and stabilization of vital signs, control of agitation with benzodiazepines, control of autonomic instability (with short acting agents such as nitroprusside and esmolol) and hyperthermia through active cooling systems [47]. Hyperthermic patients whose temperature is more than $41.1^{\circ} \mathrm{C}$ are severely ill and should receive the above-mentioned treatment as well as immediate sedation, neuromuscular paralysis (for example, vecuronium) and endotracheal intubation. The two most commonly reported beneficial drugs for treatment of serotonin syndrome acting as 5 HT2A antagonists are cyproheptadine and chlorpromazine [47]. However, their utility is purely derived from case reports and has not been wellestablished. The recommended starting dose is 50 to $100 \mathrm{mg}$ intramuscularly for chlorpromazine and 12 to $32 \mathrm{mg}$ orally for cyproheptadine during a 24 hour period, a dose that binds $85 \%$ to $95 \%$ of serotonin receptors $[6,48]$. An initial dose of $12 \mathrm{mg}$ cyproheptadine followed by $2 \mathrm{mg}$ every two hours if symptoms continue is generally recommended. Many cases of serotonin syndrome typically resolve within 24 hours after initiation of therapy and the discontinuation of serotonergic agents. However, symptoms may persist in patients taking drugs with long elimination half-lives.

\section{Uncoupling oxidative phosphorylation}

Oxidative phosphorylation requires proteins in the mitochondrial inner membrane transport chain to shuttle electrons through a series of oxidation/reduction reactions that ultimately result in oxygen being converted to $\mathrm{CO}_{2}, \mathrm{H}_{2} \mathrm{O}$ and $\mathrm{H}^{+}$, the last of which is pumped from the cytosolic side of the inner membrane into the inner membrane space. The potential energy of this gradient is then converted to ATP. When any toxin or protein short-circuits this system, this process results in the loss of potential energy being released as heat, a phenomenon known as uncoupling [49]. The most common toxins capable of uncoupling are pentachlorphenol (PCP) and salicylates [50,51].

PCP is widely used as a fungicide and wood preserver. As a lipophilic weak acid, PCP can migrate across the inner mitochondrial membrane, resulting in uncoupling leading to the production of energy in the form of heat. Thus, clinical presentation as fever, tachypnea, tachycardia, and marked diaphoresis and hyperthermia as signs of a hypermetabolic state are the most consistent findings [52]. Successful management of PCP toxicity relies on the early recognition and aggressive management of hyperthermia with passive and active cooling techniques. Given the pathophysiology of PCP toxicity, antipyretics lack any therapeutic benefit, especially the use of salicylates, which further uncouple oxidative phosphorylation. No effective antidote has been identified. Exchange transfusion has been used successfully in neonates and showed dramatic clinical improvement [53]. However, there is no controlled evidence for any form of therapy despite aggressive supportive care. 
Hyperthermia in salicylate poisoning is a sign that points to a fatal outcome if not treated aggressively and is, in part, a consequence of uncoupling. Hemodialysis is the treatment of choice both for enhancing the clearance and as a possibility to cool down the blood during extracorporeal circulation. Besides other clinical manifestations, such as intractable acidosis, renal failure, pulmonary edema, and CNS disturbances, most patients with serum salicylate concentrations greater than $100 \mathrm{mg} / \mathrm{dl}(>7.3 \mathrm{mmol} / \mathrm{l})$ eventually meet the criteria for hemodialysis [54].

\section{Malignant hyperthermia}

$\mathrm{MH}$ is not, strictly speaking, a toxin-related disturbance in temperature regulation but an adverse drug reaction. Agents inciting $\mathrm{MH}$ include inhaled volatile anesthetics and depolarizing muscle relaxants. Uncontrolled calcium release in skeletal muscle and subsequent uncoupling of oxidative phosphorylation and excessive cell metabolism are thought to be the underlying pathophysiology. Due to ATP depletion, anaerobic metabolism with metabolic acidosis and lactate production ensues. Exaggerated jaw rigidity after succinylcholine and excess of carbon dioxide production are often the first symptoms [55]. In the further course, skeletal muscle rigidity, tachycardia and hyperthermia develop. Ultimately, skeletal muscle breakdown, elevation of serum creatine kinase and hyperkalemia resulting in cardiac arrest, disseminated intravascular coagulation, and pulmonary and cerebral edema may be potentially fatal complications [56]. Susceptible persons with genetic defects in receptors controlling the release of sarcoplasmic calcium in skeletal muscle may develop symptoms after just excess exertion in warm environments [57]. Sodium dantrolene is an effective antidote for $\mathrm{MH}$. Dantrolene causes complete and sustained muscle relaxation in vivo in $\mathrm{MH}$-susceptible muscles [58]. Dosing of dantrolene is 1 to $3 \mathrm{mg} / \mathrm{kg}$ intravenously, repeated every 15 minutes as needed to a maximum dose of $10 \mathrm{mg} / \mathrm{kg}$ in the setting of acute $\mathrm{MH}$. Repeated administration of $1 \mathrm{mg} / \mathrm{kg}$ intravenously four times a day for 24 to 72 hours postoperatively prevents recurrence.

\section{Drug induced fever}

Fever and hyperthermia can be the sole manifestation of an adverse drug reaction in $3 \%$ to $5 \%$ of cases. The best definition of drug fever may be a disorder characterized by fever coinciding with drug administration and disappearing after cessation of drug administration, when no other cause for fever is evident [59]. Drug fever can occur several days after initiation of the drug, take days to subside after cessation of its administration, and produce hyperthermia with no other signs. It is essentially a diagnosis of exclusion. Mechanisms of drug fever are multifactorial and often poorly or incompletely understood. Most authorities classify drugrelated fever into five broad categories: hypersensitivity reactions, altered thermoregulatory mechanisms, directly drug induced, direct consequence of the pharmacological action of the drug and a heterogeneous group of idiosyncratic
This article is part of a review series on Toxicology, edited by Philippe Lheureux.

Other articles in the series can be found online at http://ccforum.com/articles/ theme-series.asp?series $=$ CC_Toxic

reactions [60]. Although virtually any drug is capable of causing fever via a hypersensitivity mechanism, five drugs deserve special mention due to their relative frequency at triggering drug induced fever: anticonvulsants, minocycline, antimicrobial agents, allopurinol, and heparin. The most difficult challenge for clinicians is to distinguish hyperthermia caused by infection from noninfectious fever. Most noninfectious origins of fever induce temperatures $<38.9^{\circ} \mathrm{C}$ or $>41.1^{\circ} \mathrm{C}$. Exceptions to this include drug fever, transfusion reactions, adrenal insufficiency, thyroid storm, $\mathrm{NMH}$, heat stroke and $\mathrm{MH}$. Patients with temperatures between $38.9^{\circ}$ and $41^{\circ} \mathrm{C}$ should be assumed to have an infectious cause $[61,62]$.

An integrated score called the Infection Probability Score (IPS) has been described to help assess the probability of infection in intensive care unit patients [63]. The IPS comprises variables such as temperature, heart rate, respiratory rate, white blood cell count, $\mathrm{C}$ reactive protein and Sequential Organ Failure Assessment (SOFA) score, generating a score between 0 and 26 points. Those with an IPS $\leq 14$ have only a $10 \%$ risk of infection. Fever itself - without detrimental effect on outcome - does not require treatment with antipyretics or external cooling [64]. Discontinuation of any drug not indispensable to life should be the first measure of treatment. In cases of critical hyperthermia with temperature exceeding the critical thermal maximum, thought to be between $41.6^{\circ} \mathrm{C}$ and $42^{\circ} \mathrm{C}$, rigorous supportive measures are essential.

\section{Conclusion}

There are seven different pathomechanisms of toxic substances that can lead to fever or even life-threatening hyperthermia. Treatment for each of these classes differs somewhat from cause to cause and some treatment regimens are more toxin-specific than others. All have to be treated by best intensive care support and physical cooling. Antipyretics are of no use. A temperature above $41^{\circ} \mathrm{C}$ is a sign of poor outcome if not treated aggressively, if necessary by muscle relaxation (for example, with dantrolene or vecuronium) and mechanical ventilation.

\section{Competing interests}

The authors declare that they have no competing interests.

\section{Authors' contributions}

FE contributed to the concept, design and drafting of the manuscript. TZ contributed to the concept and design and critically revised the manuscript. 


\section{References}

1. O'Grady NP, Barie PS, Bartlett J, Bleck T, Garvey G, Jacobi J, Linden P, Maki DG, Nam M, Pasculle W, et al:: Practice parameters for evaluating new fever in critically ill adult patients. Task Force of the American College of Critical Care Medicine of the Society of Critical Care Medicine in collaboration with the Infectious Disease Society of America. Crit Care Med 1998, 26:392-408.

2. Lowell BB, Spiegelman BM: Towards a molecular understanding of adaptive thermogenesis. Nature 2000, 404:652-660.

3. Charkoudian N: Skin blood flow in adult human thermoregulation: how it works, when it does not, and why. Mayo Clin Proc 2003, 78:603-612.

4. Mallick BN, Jha SK, Islam F: Presence of alpha-1 adrenoreceptors on thermosensitive neurons in the medial preopticoanterior hypothalamic area in rats. Neuropharmacology 2002, 42:697-705.

5. Landsberg L, Saville ME, Young JB: Sympathoadrenal system and regulation of thermogenesis. Am J Physiol 1984, 247: E181-189.

6. Rusyniak DE, Sprague JE: Hyperthermic syndromes induced by toxins. Clin Lab Med 2006, 26:165-184, ix.

7. Gowing LR, Henry-Edwards SM, Irvine RJ, Ali RL: The health effects of ecstasy: a literature review. Drug A/cohol Rev 2002, 21:53-63.

8. Henry JA, Jeffreys KJ, Dawling S: Toxicity and deaths from 3,4methylenedioxymethamphetamine ("ecstasy"). Lancet 1992, 340:384-387.

9. Ginsberg MD, Busto R: Combating hyperthermia in acute stroke: a significant clinical concern. Stroke 1998, 29:529-534.

10. LoVecchio F, Pizon AF, Berrett C, Balls A: Outcomes after environmental hyperthermia. Am J Emergency Med 2007, 25:442444.

11. Roberts JR, Quattrocchi E, Howland MA: Severe hyperthermia secondary to intravenous drug abuse. Am J Emergency Med 1984, 2:373.

12. Gordon NF, Duncan JJ: Effect of beta-blockers on exercise physiology: implications for exercise training. Med Sci Sports Exerc 1991, 23:668-676.

13. Steele TD, McCann UD, Ricaurte GA: 3,4-Methylenedioxymethamphetamine (MDMA, "Ecstasy"): pharmacology and toxicology in animals and humans. Addiction 1994, 89:539-551.

14. Fernandez F, Aguerre S, Mormede P, Chaouloff F: Influences of the corticotropic axis and sympathetic activity on neurochemical consequences of 3,4-methylenedioxymethamphetamine (MDMA) administration in Fischer 344 rats. Eur J Neurosci 2002, 16:607-618.

15. Zhao J, Cannon B, Nedergaard J: alpha1-Adrenergic stimulation potentiates the thermogenic action of beta3-adrenoreceptorgenerated cAMP in brown fat cells. J Biol Chem 1997, 272: 32847-32856.

16. Hadad E, Rav-Acha M, Heled Y, Epstein Y, Moran DS: Heat stroke: a review of cooling methods. Sports Med 2004, 34: 501-511.

17. Chan TC, Evans SD, Clark RF: Drug-induced hyperthermia. Crit Care Clinics 1997, 13:785-808.

18. Sprague JE, Moze P, Caden D, Rusyniak DE, Holmes C, Goldstein DS, Mills EM: Carvedilol reverses hyperthermia and attenuates rhabdomyolysis induced by 3,4-methylenedioxymethamphetamine (MDMA, Ecstasy) in an animal model. Crit Care Med 2005, 33:1311-1316.

19. Bernheim HA, Block LH, Atkins E: Fever: pathogenesis, pathophysiology, and purpose. Ann Intern Med 1979, 91:261-270.

20. Khan M, Farver D: Recognition, assessment and management of neuroleptic malignant syndrome. S D J Med 2000, 53:395400.

21. Caroff SN, Mann SC: Neuroleptic malignant syndrome. Med Clin North Am 1993, 77:185-202.

22. Rosebush PI, Stewart T, Mazurek MF: The treatment of neuroleptic malignant syndrome. Are dantrolene and bromocriptine useful adjuncts to supportive care? $\mathrm{Br} J$ Psychiatry 1991, 159:709-712

23. Carbone JR: The neuroleptic malignant and serotonin syndromes. Emerg Med Clin North Am 2000, 18:317-325, x.

24. Rosebush $\mathrm{P}$, Stewart T: A prospective analysis of $\mathbf{2 4}$ episodes of neuroleptic malignant syndrome. Am J Psychiatry 1989, 146:717-725.
25. Ananth J, Parameswaran S, Gunatilake S, Burgoyne K, Sidhom T: Neuroleptic malignant syndrome and atypical antipsychotic drugs. J Clin Psychiatry 2004, 65:464-470.

26. Chan-Tack KM: Neuroleptic malignant syndrome due to promethazine. South Med J 1999, 92:1017-1018.

27. Rainer C, Scheinost NA, Lefeber EJ: Neuroleptic malignant syndrome. When levodopa withdrawal is the cause. Postgrad Med 1991, 89:175-178, 180.

28. Caroff SN, Mann SC: Neuroleptic malignant syndrome. Psychopharmacol Bull 1988, 24:25-29.

29. Gurrera RJ, Chang SS: Thermoregulatory dysfunction in neuroleptic malignant syndrome. Biol Psychiatry 1996, 39:207212.

30. Nisijima K, Oyafuso $K$, Shimada T, Hosino $H$, Ishiguro T: Cerebrospinal fluid monoamine metabolism in a case of neuroleptic malignant syndrome improved by electroconvulsive therapy. Biol Psychiatry 1996, 39:383-384.

31. Spivak B, Maline DI, Vered Y, Kozyrev VN, Mester R, Neduva SA Ravilov RS, Graff E, Weizman A: Prospective evaluation of circulatory levels of catecholamines and serotonin in neuroleptic malignant syndrome. Acta Psychiatr Scand 2000, 102:226-230.

32. Velamoor VR: Neuroleptic malignant syndrome. Recognition, prevention and management. Drug Saf 1998, 19:73-82.

33. Hadad E, Weinbroum AA, Ben-Abraham R: Drug-induced hyperthermia and muscle rigidity: a practical approach. Eur J Emerg Med 2003, 10:149-154.

34. Adnet $\mathrm{P}$, Lestavel $\mathrm{P}$, Krivosic-Horber R: Neuroleptic malignant syndrome. $\mathrm{Br} J$ Anaesth 2000, 85:129-135.

35. Nierenberg D, Disch M, Manheimer E, Patterson J, Ross J, Silvestri $G$, Summerhill E: Facilitating prompt diagnosis and treatment of the neuroleptic malignant syndrome. Clin Pharmacol Ther 1991, 50:580-586.

36. Halloran LL, Bernard DW: Management of drug-induced hyperthermia. Curr Opin Pediatr 2004, 16:211-215.

37. Dunkley EJ, Isbister GK, Sibbritt D, Dawson AH, Whyte IM: The Hunter Serotonin Toxicity Criteria: simple and accurate diagnostic decision rules for serotonin toxicity. Q J Med 2003, 96 : 635-642.

38. Saper G: Brain stem modulation of sensation, movement, and consciousness. In Principles of Neural Science. Edited by Kendel ER, Schwartz JH, Jessel TM. New York: Mc Graw-Hill; 2000:896.

39. Mason PJ, Morris VA, Balcezak TJ: Serotonin syndrome. Presentation of 2 cases and review of the literature. Medicine 2000 79:201-209.

40. Boyer EW, Shannon M: The serotonin syndrome. N Engl J Med 2005, 352:1112-1120.

41. Mills KC: Serotonin syndrome. A clinical update. Crit Care Clinics 1997, 13:763-783.

42. Van Oekelen D, Megens A, Meert T, Luyten WH, Leysen JE: Role of $5-\mathrm{HT}(2)$ receptors in the tryptamine-induced $5-\mathrm{HT}$ syndrome in rats. Behav Pharmacol 2002, 13:313-318.

43. Packer S, Berman SA: Serotonin syndrome precipitated by the monoamine oxidase inhibitor linezolid. Am J Psychiatry 2007, 164:346-347.

44. Sampson E, Warner JP: Serotonin syndrome: potentially fatal but difficult to recognize. Br J Gen Pract 1999, 49:867-868.

45. Baigel GD: Cyproheptadine and the treatment of an unconscious patient with the serotonin syndrome. Eur J Anaesthesio 2003, 20:586-588.

46. Mills K: Serotonin syndrome. In Critical Care Toxicology: Diagnosis and Management of the Critically Poisoned Patient. Edited by Brent J, Wallace K, Burkhart K, Phillips S, Ward Donovan J. Philadelphia: Elsevier Mosby; 2005:281-290

47. Gillman PK: The serotonin syndrome and its treatment. J Psychopharmacol 1999, 13:100-109.

48. Kapur S, Zipursky RB, Jones C, Wilson AA, DaSilva JD, Houle S: Cyproheptadine: a potent in vivo serotonin antagonist. $A m ~ J$ Psychiatry 1997, 154:884.

49. Wallace KB, Starkov AA: Mitochondrial targets of drug toxicity Annu Rev Pharmacol Toxicol 2000, 40:353-388.

50. Farquharson ME, Gage JC, Northover J: The biological action of chlorophenols. Br J Pharmaco/ Chemother 1958, 13:20-24.

51. Gutknecht J: Salicylates and proton transport through lipid bilayer membranes: a model for salicylate-induced uncoupling and swelling in mitochondria. J Membr Biol 1990, 115: 253-260. 
52. Jorens PG, Schepens PJ: Human pentachlorophenol poisoning. Hum Exp Toxicol 1993, 12:479-495.

53. Robson AM, Kissane JM, Elvick NH, Pundavela L: Pentachlorophenol poisoning in a nursery for newborn infants. I. Clinical features and treatment. J Pediatr 1969, 75:309-316.

54. Chapman BJ, Proudfoot AT: Adult salicylate poisoning: deaths and outcome in patients with high plasma salicylate concentrations. Q J Med 1989, 72:699-707.

55. Denborough M: Malignant hyperthermia. Lancet 1998, 352: 1131-1136.

56. Hopkins PM: Malignant hyperthermia: advances in clinical management and diagnosis. Br J Anaesth 2000, 85:118-128.

57. Wappler F, Fiege M, Steinfath M, Agarwal K, Scholz J, Singh S, Matschke J, Schulte Am Esch J: Evidence for susceptibility to malignant hyperthermia in patients with exercise-induced rhabdomyolysis. Anesthesiology 2001, 94:95-100.

58. Ward A, Chaffman MO, Sorkin EM: Dantrolene. A review of its pharmacodynamic and pharmacokinetic properties and therapeutic use in malignant hyperthermia, the neuroleptic malignant syndrome and an update of its use in muscle spasticity. Drugs 1986, 32:130-168.

59. Mackowiak PA, LeMaistre CF: Drug fever: a critical appraisal of conventional concepts. An analysis of 51 episodes in two Dallas hospitals and 97 episodes reported in the English literature. Ann Intern Med 1987, 106:728-733.

60. Johnson DH, Cunha BA: Drug fever. Infect Dis Clin North Am 1996, 10:85-91.

61. Cunha BA: Fever in the critical care unit. Crit Care Clinics 1998, 14:1-14

62. Marik PE: Fever in the ICU. Chest 2000, 117:855-869.

63. Peres Bota D, Melot C, Lopes Ferreira F, Vincent JL: Infection Probability Score (IPS): A method to help assess the probability of infection in critically ill patients. Crit Care Med 2003, 31:2579-2584.

64. Ryan M, Levy MM: Clinical review: fever in intensive care unit patients. Crit Care 2003, 7:221-225. 